\title{
An analysis of the semantic variability of weak adjuncts and its problems ${ }^{1}$
} Sarah ZOBEL - University of Tuebingen

\begin{abstract}
This paper addresses the question of how to account for the semantic variability of weak free adjuncts. Weak free adjuncts are non-clausal adjuncts that associate with an argument of the main predicate, contribute propositional content, and can interact with temporal or modal operators, which leads to different, adverbial-clause-like interpretations. I focus on a specific type of weak adjuncts, non-clausal as-phrases, and propose a unified semantic analysis for the full range of interpretational possibilities that takes into account the interpretational contingency on different syntactic positions. I show that this analysis improves on Stump's (1985) original analysis of weak adjuncts. I then go on to discuss the limitations of both Stump's account and the unified account. Both accounts fail to capture that the interaction of weak adjuncts with modal operators underlies certain restrictions on the properties of the modal operators-an observation that has not been discussed in the literature so far.
\end{abstract}

Keywords: weak free adjuncts, semantic variability, as-phrases, temporal/modal operators.

\section{Introduction}

Free adjuncts are non-clausal adjuncts that associate with an argument of the main predicate (the "associated constituent") and contribute propositional content about the denotation of that argument (the "associated individual"). Types of free adjuncts are, for instance, nominal, nonclausal as-phrases, see (1), and non-clausal phrases headed by gerunds, see (2). ${ }^{2}$ While all free adjuncts fall under the above description, Stump (1985) notes that some free adjuncts give rise to an ambiguity in the case that they co-occur with a temporal or modal operator, see the asphrases in (1). Stump calls free adjuncts of this kind "weak (free) adjuncts" and free adjuncts that do not give rise to such an ambiguity "strong (free) adjuncts".

a. As a child, Peter got in for free.

(past tense operator)

(Possible: When Peter was a child, he got in for free.)

(Possible: Since Peter is/was a child, he got in for free.)

b. As a child, Peter would get in for free.

(would, modal operator)

(Possible: Since Peter is a child, he would get in for free.)

(Possible: If Peter were a child, he would get in for free.)

Sentences that contain a weak adjunct and a temporal/modal operator can be interpreted in such a way that the weak adjunct contributes causal-clause-like content (paraphrasable by a since-clause) and/or either temporal-clause-like or conditional-antecedent-like content (de-

\footnotetext{
${ }^{1}$ I would like to thank Ryan Bochnak, Kai von Fintel, Nina Haslinger, Irene Heim, Carina Kauf, Magda Kaufmann, Stefan Kaufmann, Edith Scheifele, Thomas Weskott, as well as the audiences at Sinn und Bedeutung 22 (Potsdam), LingLunch (MIT), the Meaning Group (UConn), and the colloquium at the German Department of the University of Vienna for helpful questions and discussion. This work was supported by a postdoc fellowship of the German Academic Exchange Service (DAAD).

${ }^{2}$ The as-phrases discussed in this paper are Class 4 as-phrases following the classification of English non-clausal as-phrases in Zobel 2016, 2017a.
} 
pending on the co-occurring type of operator), compare (1a) and (1b). For weak adjuncts in episodic sentences in the present tense (e.g., as a child, Peter is getting in for free), only the causal-clause-like interpretation is available. For strong adjuncts, by contrast, the presence of a temporal/modal operator has no effect. They always contribute causal-clause-like content, see being a child in (2).

(2) Being a child, Peter would get in for free.

(strong)

(Only possible: Since Peter is a child, he would get in for free.)

(Not possible: If Peter were a child, he would get in for free.)

Stump (1985) proposes the first formal semantic account for the semantic variability of weak adjuncts in the context of Montague grammar. His main strategy for capturing the range of observed contributions is to derive them using tailor-made semantic transformations. The first major aim of this paper is to present an analysis of weak adjuncts and their semantic variability that (i) retains Stump's general intuitions about the semantic contribution of weak adjuncts but (ii) derives these from a unified proposal for the semantics of weak adjuncts without recourse to semantic transformations. The second major aim is to address the predictions and limitations of Stump's proposal and this unified account. A closer look at the interaction of weak adjuncts and modal auxiliaries will yield further desiderata for an adequate analysis of weak adjuncts, which are not met by either proposal.

The paper is structured as follows. Section 2 provides a brief characterization of Stump's formal proposal. In Section 3, I present an alternative, unified analysis of weak adjuncts that takes their semantic variability to be a result of the relative flexibility of weak adjuncts with respect to their syntactic adjunction sites. The limitations of both Stump's and the alternative account are discussed in Section 4. There, I show that the interaction between weak adjuncts and modal operators is much more restricted than previously assumed, and that these restrictions are also in effect with other semantic phenomena. Section 5 concludes the paper.

\section{Stump's (1985) analysis of the semantic variability of weak free adjuncts}

In his dissertation, Stump (1985) presents a fully worked out Montague fragment ${ }^{3}$ of English that is designed to deal specifically with the semantics of free adjuncts. The fragment is comprised of (i) a categorial grammar, (ii) an intensional logic, and (iii) a syntax-semanticsinterface (i.e., a list of interpretation rules) that translates syntactic structures into logical expressions. For each node in a syntactic structure, the syntax-semantics-interface provides a category-specific interpretation rule. These rules are sensitive to the semantic type and features of the node's daughter expressions (i.e., the argument expression(s) of the rule), and the result of applying these rules in a step-wise manner are $\lambda$-expressions that are part of the intensional logic. In addition to effecting composition of their arguments, the interpretation rules may introduce additional, potentially underspecified material (e.g., free variables) into the resulting $\lambda$-expressions, which are valued subsequently via a pragmatic process. ${ }^{4}$

\footnotetext{
${ }^{3}$ A Montague fragment is a formal system for the analysis of natural language in the spirit of the work of Richard Montague, e.g., modelled after Montague 1973.

${ }^{4}$ For a more elaborate exposition of Stump's system, I ask the interested reader to directly refer to Stump 1985.
} 
The main tenet of Stump's proposal for weak adjuncts is that they are semantically variable because their semantic contribution in each specific instance can parallel that of the adverbial clause with which they are paraphrased. Formally, this is implemented by dedicated interpretation rules that transform the basic semantic contribution of weak adjunct $a s$-phrases in such a way that the resulting semantics mirrors the contribution and compositional behavior of the corresponding adverbial clauses. The basic semantic contribution of weak and strong free adjuncts, according to Stump, describes a set of times; (3) provides the basic semantics for as a child. ${ }^{5}$

$$
\begin{aligned}
& \lambda t . \operatorname{AT}\left(t, \exists x^{s}\left[\mathrm{R}\left(x^{s}, y^{i}\right) \& \exists z^{i}\left[\mathrm{R}\left(x^{s}, z^{i}\right) \& \text { child' }\left(z^{i}\right)\right]\right]\right) \\
& \Leftrightarrow \lambda t . \operatorname{AT}\left(t, \exists x^{s}\left[\mathrm{R}\left(x^{s}, y^{i}\right) \& \text { child' }\left(y^{i}\right)\right]\right)
\end{aligned}
$$$$
\text { (type }\langle i, t\rangle \text { ) }
$$

IN PROSE: The set of times $t$ such that $y$ 's stage $x$ at $t$ is a child-stage. ${ }^{6}$

Notably, this basic meaning never directly combines with other expressions to derive the various interpretations observed for weak adjuncts. In each specific instance, it is first transformed (guided by the "right" syntactic categories) into expressions that parallel the corresponding adverbial clauses. This means, of course, that the semantic contribution of one and the same weak adjunct can differ quite radically depending on its use. Example (4) shows the result of applying the relevant rules to (3) to capture the causal-clause-like and the conditional-antecedent-like uses exhibited by as a child in (1b).

$$
\begin{array}{ll}
\text { a. } & \text { As a child interpreted as a causal clause: } \\
& \lambda P . \lambda t . \mathscr{K}(\mathrm{L})\left(\exists t^{\prime}\left[\mathrm{M}\left(t, t^{\prime}\right) \& \operatorname{AT}\left(t^{\prime}, \exists x^{s}\left[\mathrm{R}\left(x^{s}, y^{i}\right) \& \text { child }{ }^{\prime}\left(y^{i}\right)\right]\right)\right]\right)(P(t)) \\
\text { b. } & \text { As a child interpreted as a conditional antecedent: } \\
& \exists t\left[\operatorname{AT}\left(t, \exists x^{s}\left[\mathrm{R}\left(x^{s}, y^{i}\right) \& \text { child' }\left(y^{i}\right)\right]\right)\right]
\end{array}
$$

The expression in (4a) denotes a modifier that takes the contribution of the main clause as an argument $(P)$ and relates the proposition $P(t)$ via some contextually determined (typically, causal) relation $L$ to the proposition built from the basic contribution of the weak adjunct (first argument of $\mathscr{K}(\mathrm{L})$ ). In contrast, the expression in (4b) simply denotes a proposition (i.e., there is a time $t$ at which the content contributed by the weak adjunct holds). The conditionalantecedent-like interpretation, Stump proposes (following Kratzer 1977), arises from using (4b) as the first argument/restrictor of a co-occurring modal quantifier.

In the introduction, we have seen that weak adjuncts can also interact with past tense in episodic sentences, see (1a). Stump does not discuss this case. Given the proposed parallelism between weak adjuncts and adverbial clauses, he arguably would have suggested an analysis that parallels that of temporal adverbial clauses, which are of type $\langle\langle i, t\rangle,\langle i, t\rangle\rangle$. To analyze this case adequately, new interpretation rules are needed, though. ${ }^{7}$

\footnotetext{
${ }^{5}$ Stump proposes a semantics for $a s$, but never explicitly analyzes full $a s$-phrases. The analyses in (3) and (4) are the result of applying Stump's rules to his denotation for as and indefinite NPs. I also slightly modernize Stump's notation. The superscripts on $x, y$, and $z$ indicate whether a variable ranges over individuals $(i)$ or stages $(s)$ and $R$ is the relation that relates individuals and their stages in the sense of Carlson 1977.

${ }^{6}$ The variable $y$ is contextually identified with the associated individual.

${ }^{7}$ Even though (4a) has type $\langle\langle i, t\rangle,\langle i, t\rangle\rangle$, it would not provide the right semantic contribution for the temporalclause-like cases given Stump's own analysis of temporal adverbial clauses.
} 
While Stump's proposal manages to capture the semantic variability of weak adjuncts, his analysis is ultimately dissatisfying. As described above, his main strategy is to introduce tailormade interpretation rules to capture each of the interpretational possibilities of weak adjuncts. This results in an analysis that only restates the main observation-i.e., weak adjuncts are flexible with respect to which relation is understood to hold between their contribution and the content contributed by the main clause.

In the following section, I use the case of weak adjunct $a s$-phrases to show that in a system that follows the general principles outlined in Heim and Kratzer 1998, the central observation that weak adjuncts can behave like different adverbial clauses can be captured without recourse to specialized interpretation rules. The main assumption underlying this account is that weak adjuncts are flexible with respect to where they are base generated and interpreted. ${ }^{8}$

\section{A unified analysis of the semantic variability of weak adjunct as-phrases}

\subsection{The semantic contribution of as-phrases}

To start out, I propose a basic analysis of weak adjunct as-phrases. Following Emonds (1984), Stump (1985), and Jäger (2003), I assume that as serves a function similar to that of the copula in predicational copular sentences. ${ }^{9}$ Recent analyses of predicational copular clauses assume that the copula takes only one argument, a Small Clause (i.e., a phrase that contains both a non-verbal predicate and its subject; see e.g., Matushansky and Spector 2005). Consider (5).
a. Peter is a child.
b. $\quad[v P$ is $[S C$ Peter $[D P$ a child $]]]$

I directly adopt this idea for my proposal for the syntactic structure of $a s$-phrases in (6).

$$
\left[\text { asP as }\left[{ }_{S C} \text { PRO [DP a child] }\right]\right]
$$

Unlike the Small Clauses in copular sentences, a Small Clause in the complement of as does not have an overt subject but contains the covert pronoun PRO. The semantic value of PRO is provided by the associated constituent (i.e., the argument of the main predicate with which the as-phrase associates; see the introduction). Following Williams (1992), Adler (2006), and Flaate (2007), I assume that this association dependency can be captured formally by assuming that PRO is non-obligatorily controlled by that associated argument.

Semantically, as, just like the copula, contributes an identity function over propositions (cf. Matushansky and Spector 2005). That is, as takes a propositional argument $p$ (type $\langle i,\langle s, t\rangle\rangle$ ) and returns it unchanged, see (7). ${ }^{10}$

\footnotetext{
${ }^{8}$ Stump employs categorial grammar to analyze sentences close to their surface. Hence, the avenue to link the observed semantic flexibility to an underlying structural difference that is resolved by movement (see below) is not open to him.

${ }^{9}$ Emonds (1984) calls as a/the "prepositional copula".

${ }^{10}$ This analysis ignores the differences between as and the copula. For a discussion of these differences see Stump 1985 and Jäger 2003.
} 


$$
\llbracket \mathrm{as} \rrbracket^{w_{0}, t_{0}, g}=\lambda p_{\langle i,\langle s, t\rangle\rangle} \cdot p
$$

(type $\langle\langle i,\langle s, t\rangle\rangle,\langle i,\langle s, t\rangle\rangle\rangle)$

The Small Clause in the complement of as contributes propositional content, see (8); for the purposes of this analysis, I assume that the referent of PRO, which is determined via nonobligatory control, is assigned by the variable assignment $g .{ }^{11}$

$$
\llbracket\left[S C \mathrm{PRO}_{i} \text { a child }\right] \rrbracket^{w_{0}, t_{0}, g}=\lambda t \cdot \lambda w \cdot \operatorname{child}^{\prime}(g(i))(t)(w)
$$

$$
\text { (type }\langle i,\langle s, t\rangle\rangle \text { ) }
$$

To derive the contribution of the full as-phrase in (6), we need to combine (7) with (8). Given that as contributes an identity function, the result of this combination in (9) is identical to (8).

$$
\llbracket \text { as }[S C \text { PRO a child }] \rrbracket^{w_{0}, t_{0}, g}=\lambda t \cdot \lambda w \cdot \text { child' }^{\prime}(g(i))(t)(w)
$$

IN PROSE: The proposition that is true for a world $w$ and a time $t$ iff the associated individual $g(i)$ is a child at $t$ in $w$.

The proposal in (9) directly mirrors Stump's basic meaning in (3). In contrast to Stump, I argue that (9) suffices to capture the full range of interpretations given one basic assumption: weak adjunct $a s$-phrases can be base generated wherever they are interpretable (i.e., wherever they can be composed with their sister nodes). The sentence-initial position found for the full range of possible interpretations of as a child in (1) is the result of movement from different underlying base positions. This movement is later reconstructed at LF prior to interpretation. ${ }^{12}$

Which positions are viable base positions for weak adjuncts is determined by the syntactic and semantic status of weak adjuncts. Since they are modifiers, I assume that they combine with the denotations of their sister nodes via a generalized form of Predicate Modification (Heim and Kratzer 1998). Hence, as-phrases can adjoin to any node of type $\langle i,\langle s, t\rangle\rangle$.

Which nodes are of type $\langle i,\langle s, t\rangle\rangle$ ? For the basic syntactic structure of a sentence, I adopt the sequence of functional projections in Beck and von Stechow 2015, see (10). Furthermore, I follow their assumption that the lexical material below AspP jointly builds up a time- and world-independent eventuality description. Unlike Beck and von Stechow (2015), however, I assume that, after existential closure of this eventuality description by the head of Asp, the branching nodes along the functional spine have a uniform semantic type; they are all timeand world-dependent (i.e., of type $\langle i,\langle s, t\rangle\rangle){ }^{13}$

\footnotetext{
${ }^{11}$ To my knowledge, there is no established semantic proposal for how to model non-obligatory control into adjuncts that attach high in the syntactic structure. For a discussion of the properties of this type of control see Adler 2006. For the moment, I assume that the value assigned by $g$ is fixed by some independent mechanism.

${ }^{12}$ This predicts that the sentence-initial position is not the only position in which weak adjunct $a s$-phrases are found. This is borne out: they can also occur in sentence-final position.

(i) ?Peter gets in for free as a child.

The slight marginality of (i), I suggest, arises because sentence-final as-phrases are preferably read as as-phrases of Class 3; these are as-phrases that specify the role or function in which the associated individual participated in the eventuality described by the main predicate (see Zobel 2016, 2017a).

${ }^{13}$ I diverge from Beck and von Stechow (2015) in how I model intensionality because, unlike these authors, I do not assume that time/world variables and their binders are syntactically represented.
} 


$$
\begin{aligned}
& \mathrm{CP}-\mathrm{TP}(\text { tense })-\mathrm{IP}(\text { modals })-\mathrm{AspP}(\text { aspect })-\mathrm{vP} / \mathrm{VP} \\
& <- \text { potential adjunction sites }-><- \text { no adjunction }->
\end{aligned}
$$

The semantic variability of weak adjuncts can now be reduced to the different adjunction sites occupied by different weak adjuncts. Specifically, the choice of adjunction site will determine which of the operators introduced in the functional heads along this spine will be able to interact with the content contributed by the weak adjunct. Any operator that has scope over the weak adjunct will have an effect on the time or world of evaluation of its content. For operators that sit in a position below the base-generation site of the weak adjunct, though, the adjunct and its time and world of evaluation will be "out of reach". What this means for specific cases is made explicit in the upcoming subsections.

\subsection{The temporal-clause-like interpretation}

The temporal-clause-like interpretation of weak adjuncts arises from the interaction of their content with a temporal operator. In the case of (1a) (i.e., As a child, Paul got in for free), for instance, the temporal-clause-like interpretation arises from the $a s$-phrase being adjoined to a node in the scope of the temporal operator [PAST], see (11).

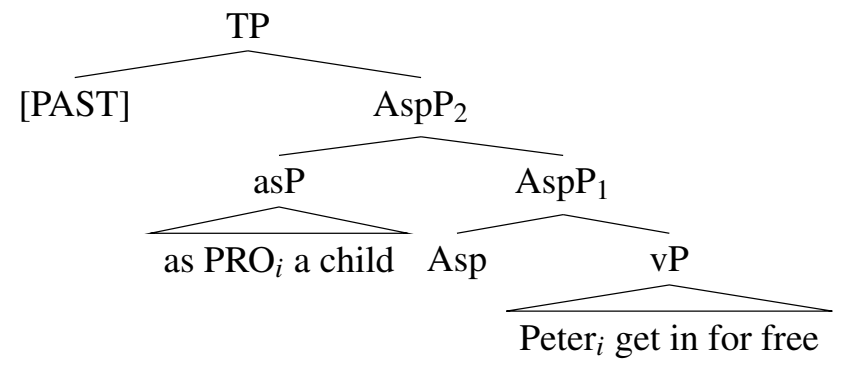

To derive the semantics of (11), I start out by assuming that $\mathrm{AspP}_{1}$ has the denotation in (12).

$$
\begin{aligned}
& \llbracket\left[{ }_{A s p P_{1}} \text { Asp Peter }_{i} \text { get in for free }\right] \rrbracket^{w_{0}, t_{0}, g}= \\
& \left.\lambda t^{\prime} \cdot \lambda w . \exists e\left[e \text { in } w \& t^{\prime} \supseteq \tau(e) \& \text { get-in-for-free'(Peter }\right)(e)\right]
\end{aligned}
$$

Since $\operatorname{AspP}_{1}$ is of type $\langle i,\langle s, t\rangle\rangle$, its contribution in (12) and the contribution of the as-phrase in (9), which is also of type $\langle i,\langle s, t\rangle\rangle$, can be composed using Generalized Predicate Modification, which results in the denotation of $\mathrm{AspP}_{2}$ in (13). ${ }^{14}$

$$
\begin{aligned}
& \llbracket\left[A s p P_{2} \text { as a child } \ldots \text { free }\right] \rrbracket^{w_{0}, t_{0}, g}= \\
& \left.\quad \lambda t^{\prime} . \lambda w \text {. child' }(g(i))\left(t^{\prime}\right)(w) \& \exists e\left[e \text { in } w \& t^{\prime} \supseteq \tau(e) \& \text { get-in-for-free'(Peter }\right)(e)\right]
\end{aligned}
$$

Next, the denotation of [PAST], given in (14), is applied to (13). This results in the final proposal for the denotation of (11) in (15).

\footnotetext{
${ }^{14}$ The effect of applying Generalized Predicate Modification to two functions of the same type $\left\langle\alpha_{1}, \ldots\left\langle\alpha_{n}, t\right\rangle \ldots\right\rangle$ is (i) identification of the arguments of matching types in the order in which they are given and (ii) conjunction of the descriptive material. The resulting expression also has the type $\left\langle\alpha_{1}, \ldots\left\langle\alpha_{n}, t\right\rangle \ldots\right\rangle$.
} 


$$
\llbracket[\mathrm{PAST}] \rrbracket^{w_{0}, t_{0}, g}=\lambda p_{\langle i,\langle s, t\rangle\rangle} \cdot \lambda t \cdot \lambda w \cdot \exists t^{\prime}\left[t^{\prime} \leq t \& p\left(t^{\prime}\right)(w)\right]
$$

$\lambda t . \lambda w . \exists t^{\prime}\left[t^{\prime} \leq t \&\right.$ child' $^{\prime}(g(i))\left(t^{\prime}\right)(w) \& \exists e\left[e\right.$ in $w \& t^{\prime} \supseteq \tau(e) \&$ g-i-f-f'(Peter $\left.\left.)(e)\right]\right]$ IN PROSE: (15) holds for a world $w$ and a time $t$ iff there is a time $t^{\prime}$ preceding $t$ such that Peter is a child at $t^{\prime}$ in $w$ and $t^{\prime}$ includes the runtime of an event $e$ of Peter getting in for free in $w$.

The effect of [PAST] is to shift the time $t^{\prime}$ (i.e., the reference/topic time of the clause) into the past of the overall time of evaluation $t$ of the sentence. One result of the composition step illustrated in (13) is the identification of the temporal argument of the as-phrase content with the temporal argument of the denotation of $\mathrm{AspP}_{1}$. As a result of this identification, the asphrase content further specifies the reference/topic time $t^{\prime}$ in (15). Since further specifying the reference/topic time $t^{\prime}$ is the task that is usually served by temporal adverbials, the present proposal manages to capture the temporal-clause-like interpretation of weak adjunct as-phrases that arises as a result of the semantic interaction with temporal operators like [PAST].

\subsection{The conditional-antecedent-like interpretation}

The conditional-antecedent-like interpretation observed for weak adjunct $a s$-phrases arises as a result of their interaction with modal operators. For instance, the conditional-like interpretation of (1b) (i.e., If Peter were a child, he would get in for free) can be attributed to the interaction of the as-phrase content with the modal operator contributed by would.

To capture this interpretation of (1b), I adopt Stump's basic idea that if an as-phrase co-occurs with a modal auxiliary, it can restrict the modal quantifier contributed by this auxiliary in the same manner as an if-clause. Instead of taking if-clauses to be arguments of modal auxiliaries (see Stump's proposal in Section 2), however, I adopt the basic syntactic and semantic analysis of conditionals in von Stechow 2004. Following von Stechow, I assume that if-clauses modify a free variable $f_{c b}$, which is an argument of the modal auxiliary and contributes its conversational background (i.e., the restrictor). The value of $f_{c b}$ is a proposition (type $\langle i,\langle s, t\rangle\rangle$ ); it is the conjunction of all contextually determined background assumptions with respect to which the necessity or possibility expressed by the corresponding modal auxiliary is determined (see Kratzer 2012). Since $a s$-phrases can be adjoined to any node of type $\langle i,\langle s, t\rangle\rangle$ (see Section 3.1), they can also adjoin to $f_{c b}$.

For (1b), the conditional-antecedent-like interpretation arises as a result of the as-phrase modifying the value assigned to the variable $f_{c b}$, which contributes the restrictor of the co-occurring modal operator contributed by would, see (16). ${ }^{15}$

\footnotetext{
${ }^{15}$ Following Ippolito (2013) among others, I take would to spell out the universal modal operator WOLL in the scope of [PAST]. Since the question whether [PAST] in this context expresses regular temporal precedence or so-called "fake past" is orthogonal to my concerns (but see the discussion in Ippolito 2013), I arbitrarily assign to $[\mathrm{PAST}]$ its regular temporal interpretation.
} 


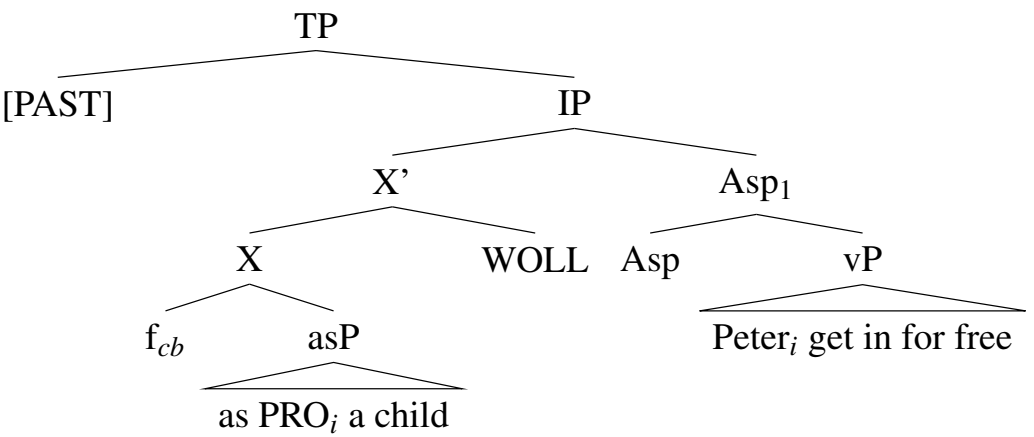

To start out, let us first derive the contribution of the modal restricted by $f_{c b}$ after it has been modified by the $a s$-phrase (i.e., the denotation of the $X^{\prime}$-node). First, I assume that WOLL expresses universal quantification over worlds. It takes two propositional arguments: its restrictor $q$ and its scope $p$, see (17).

$$
\llbracket \mathrm{WOLL} \rrbracket^{w_{0}, t_{0}, g}=\lambda q_{\langle i,\langle s, t\rangle\rangle} \cdot \lambda p_{\langle i,\langle s, t\rangle\rangle} \cdot \lambda t \cdot \lambda w \cdot \forall w^{\prime}: q(t)\left(w^{\prime}\right)\left[p(t)\left(w^{\prime}\right)\right]
$$

Second, the denotation of the $X$-node, which contributes the modified restrictor for WOLL and fills its first propositional argument, is derived by applying Generalized Predicate Modification to $f_{c b}$ and the $a s$-phrase content, see (18).

$$
\llbracket\left[X \mathrm{f}_{c b} \text { as a child } \rrbracket^{w_{0}, t_{0}, g}=\lambda t \cdot \lambda w \cdot f_{c b}(t)(w) \& \text { child' }(g(i))(t)(w)\right.
$$

After applying (17) to (18), we obtain the denotation in (19) for the $X^{\prime}$-node. The $X^{\prime}$-node denotes a modal operator that takes a proposition $p$, a world $w$, and a time $t$ as its arguments and outputs true iff for all worlds $w^{\prime}$ in which $f_{c b}$ is true at $t$ and $g(i)$ is a child at $t$, the proposition $p$ is true at $t$ in $w^{\prime}$.

$$
\llbracket \mathrm{X}^{\prime} \rrbracket^{w_{0}, t_{0}, g}=\lambda p_{\langle i,\langle s, t\rangle\rangle} \cdot \lambda t \cdot \lambda w \cdot \forall w^{\prime}: f_{c b}(t)\left(w^{\prime}\right) \& \operatorname{child}^{\prime}(g(i))(t)\left(w^{\prime}\right)\left[p(t)\left(w^{\prime}\right)\right]
$$

The propositional argument slot of (19) is filled in the next composition step by the denotation of $\mathrm{AspP}_{1}$ in (20) (repeats (12)). The result is given in (21).

$$
\begin{aligned}
& \llbracket\left[A s p P_{1} \text { Asp Peter }{ }_{i} \text { get in for free }\right] \rrbracket^{w_{0}, t_{0}, g}= \\
& \left.\lambda t^{\prime} . \lambda w . \exists e\left[e \text { in } w \& t^{\prime} \supseteq \tau(e) \& \text { get-in-for-free'(Peter }\right)(e)\right] \\
& \llbracket\left[I P \mathrm{f}_{c b} \ldots \text { for free }\right] \rrbracket^{w_{0}, t_{0}, g}=\lambda t^{\prime} \cdot \lambda w \cdot \forall w^{\prime}: f_{c b}\left(t^{\prime}\right)\left(w^{\prime}\right) \& \text { child' }(g(i))\left(t^{\prime}\right)\left(w^{\prime}\right)[ \\
& \left.\left.\exists e\left[e \text { in } w^{\prime} \& t^{\prime} \supseteq \tau(e) \& \text { get-in-for-free'(Peter }\right)(e)\right]\right]
\end{aligned}
$$

In the last composition step, the denotation of [PAST] (see (14) in Section 3.2) is applied to (21). By this, we obtain the final proposal in (22) for the denotation of (16).

$$
\begin{array}{r}
\lambda t . \lambda w . \exists t^{\prime}\left[t^{\prime} \leq t \& \forall w^{\prime}: f_{c b}\left(t^{\prime}\right)\left(w^{\prime}\right) \& \text { child' }(g(i))\left(t^{\prime}\right)\left(w^{\prime}\right)[\right. \\
\left.\left.\left.\exists e\left[e \text { in } w^{\prime} \& t^{\prime} \supseteq \tau(e) \& \text { get-in-for-free'(Peter }\right)(e)\right]\right]\right]
\end{array}
$$

IN PROSE: (22) holds for $t$ and $w$ iff there is time $t^{\prime}$ preceding $t$ such that for all worlds $w^{\prime}$ in which $f_{c b}$ holds at $t^{\prime}$ and Peter is a child at $t^{\prime}$, there is an event $e$ at $t^{\prime}$ of Peter getting in for free. 
As in Section 3.2, the desired interpretation is ensured by the assumption that as-phrases can be base generated and interpreted in any position in which they are sister to a node of type $\langle i,\langle s, t\rangle\rangle$. Hence, the conditional-antecedent-like interpretation and the temporal-clause-like interpretation are captured in an entirely parallel fashion. ${ }^{16}$

\subsection{The causal-clause-like interpretation}

The causal-clause-like interpretation has a special status among the potential interpretations of weak adjuncts. It is the only interpretation that is always available, regardless of any cooccurring temporal or modal operators; and it is the only interpretation that is also available for strong free adjuncts (see the introduction).

Recall the strategy that was pursued in the previous subsections to model the interaction with temporal/modal operators: the $a s$-phrase was argued to adjoin in a position where it directly modifies the restrictor or scope of a given operator. This ensures that the time and/or world argument inside the $a s$-phrase content becomes dependent on this operator. Hence, to capture the independence of the causal-clause-like interpretation, I assume that the as-phrase adjoins to a position in the clause that is outside the scope of any temporal/modal operator. ${ }^{17}$ In what follows, I discuss this idea based on the example of the causal-clause-like interpretation of (1a) (i.e., As a child, Paul got in for free), see the syntactic structure in (23).

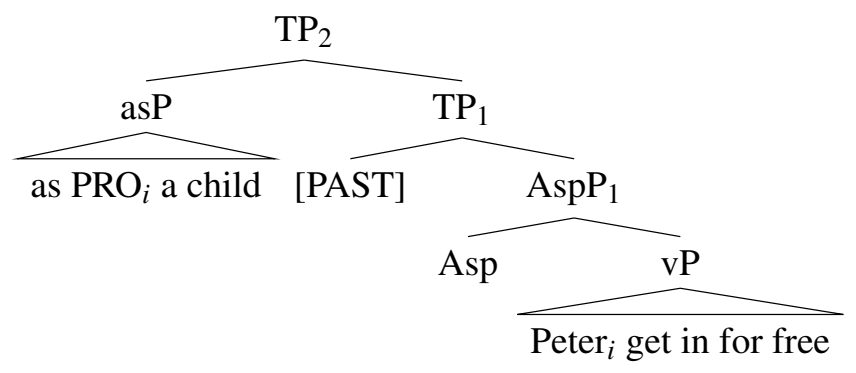

To derive the interpretation of (23), the temporal operator [PAST] (see Section 3.2) first composes with the denotation of $\mathrm{AspP}_{1}(=(20))$. This results in the denotation of $\mathrm{TP}_{1}$ in (24).

$$
\begin{aligned}
& \llbracket\left[T P_{1} \text { [PAST] Asp Peter get in for free }\right] \rrbracket^{w_{0}, t_{0}, g}= \\
& \left.\qquad \lambda t . \lambda w \cdot \exists t^{\prime}\left[t^{\prime} \leq t \& \exists e\left[e \text { in } w \& t^{\prime} \supseteq \tau(e) \& \text { get-in-for-free'(Peter }\right)(e)\right]\right]
\end{aligned}
$$

\footnotetext{
${ }^{16}$ The analysis provided in this subsection could in principle be adapted for an analysis of modal auxiliaries that utilizes a modal base and an ordering source: all steps that involve $f_{c b}$ have to be performed for a variable of type $\langle i,\langle s, t\rangle\rangle$ that brings in the modal base of the corresponding modal auxiliary (see Kratzer 2012).

${ }^{17}$ This is not to say that strong free adjuncts can only adjoin to positions outside the scope of temporal and modal operators. There might be other reasons for why strong free adjuncts and these operators do not interact. Stump (1985), for instance, argues that strong free adjuncts are individual level predicates, while weak free adjuncts are stage level predicates. This distinction, Stump suggests, has an impact on their semantic behavior and prevents strong free adjuncts from scoping under temporal and modal operators. Jäger (2003) translates this into the idea that weak free adjuncts can take small situation-sized arguments, while strong free adjuncts can only be predicated of world-sized arguments and, hence, cannot restrict temporal/modal quantifiers. I remain agnostic regarding the difference between weak and strong free adjuncts as this question is orthogonal to the present concerns.
} 
The denotation of $\mathrm{TP}_{1}$ is of type $\langle i,\langle s, t\rangle\rangle$. Hence, (24) can be composed with the denotation of the adjoined $a s$-phrase via Generalized Predicate Modification. The result is given in (25).

$$
\left.\lambda t . \lambda w \text {. child' }(g(i))(t)(w) \& \exists t^{\prime}\left[t^{\prime} \leq t \& \exists e\left[e \text { in } w \& t^{\prime} \supseteq \tau(e) \& \text { g-i-f-f'(Peter }\right)(e)\right]\right]
$$

IN PROSE: (25) holds for $w$ and $t$ iff Peter is child at $t$ in $w$, and there is a time $t^{\prime}$ preceding $t$ that includes the runtime of an event $e$ in $w$ of Peter getting in for free.

Since the as-phrase is adjoined in a position above TP, the time and world of evaluation for the $a s$-phrase content are the time $t$ and world $w$ of evaluation of the entire sentence, which are pragmatically identified with the time $t_{0}$ and world $w_{0}$ of utterance.

How does (25) capture the causal-clause-like interpretation of (1a)? The short answer is: it doesn't. As it stands, the result in (25) of the step-wise interpretation procedure is semantically equivalent to Peter is a child, (and) he got in for free. I assume, following Jäger (2003), that the explanation relation between the first and the second conjunct in (25) is inferred pragmatically using the same mechanism that allows us to infer similar discourse relations between independent utterances, as in (26) (see Asher and Lascarides 2003).

Peter got in for free. He is a child.

The two sentences in (26) are preferably understood such that the second sentence provides an explanation for the validity of the first sentence. Similarly, the content contributed by the $a s$-phrase is understood as providing an explanation for the validity of the content contributed by the remaining material in the clause.

Of course, this parallel between (1a) and (26) is only suggestive. A fully worked-out proposal has to be left for future work. I will, however, discuss two observations that concern the optionality of the explanation relation, which supports the decision not to hard-code an explanation relation into the denotation of weak adjunct as-phrases.

First, we observe that the explanation relation understood in the context of the causal-clauselike interpretation is not obligatorily present in the temporal-clause-like interpretation. Example (27), for instance, does not convey that Peter's being a child explains his being blond—only that Peter was blond when he was a child. If an explanation relation were an integral part of the semantics of $a s$-phrases, this strict temporal contribution could not be explained. ${ }^{18}$

$$
\text { As a child, Peter had blond hair. }
$$

Second, the explanation relation only seems to be the default link that is inferred to connect the propositional as-phrase content and the proposition expressed by the remainder of the sentence. In the right supporting contexts we can also infer a concessive relation, see (28).

$$
\text { I was shocked by Peter's confession. As a doctor, he smokes } 50 \text { cigarettes a day! }
$$

\footnotetext{
${ }^{18}$ The same, in fact, holds for the conditional-antecedent-like interpretation, but this may be harder to see because of the rule-like connection between the restrictor and the scope that is established by the modal operator.
} 
In the given context, the second sentence in (28) is most naturally understood as conveying that Peter smokes 50 cigarettes a day even though he is a doctor (i.e., doctors usually do not smoke 50 cigarettes a day). Crucially, we do not interpret his being a doctor as an explanation for his smoking habits.

At the moment, the exact conditions that underlie the causal-clause-like and the concessiveclause-like interpretations are unclear to me. What is clear, though, is that the relation that is to be understood cannot be attributed to the semantics of the as-phrase or any co-occurring operator. I need to leave the missing details for further investigation.

\subsection{Comparing Stump's original account to the present proposal}

The aim for the proposal outlined in Sections 3.1-3.4 was to capture the same range of interpretations as Stump's account. The resulting proposal is, however, not "just" a translation of Stump's account into another system. In this subsection, I show that the two accounts differ in their predictions, and that the present proposal captures patterns in the data that Stump's account fails to predict. The present analysis, therefore, must be seen as a refinement of Stump's.

The relevant data concerns the possible interpretation of sentences that contain two as-phrases (one sentence-initially and one sentence-finally, see fn. 12) and a co-occurring temporal or modal operator, as in (29).

a. As a shy person, Peter was quiet as a child.

b. As a runner, Peter would have fun as a participant of this course. (would)

We observe that the relative positions of the two as-phrases in a clause constrain the possible interpretations of the two occurrences. Even though (29a) contains two as-phrases that could in principle both interact with [PAST], only the second as-phrase, as a child, can (and indeed must) interact with it. The first as-phrase, as a shy person, can only be given a causal-clauselike interpretation. Analogously in (29b), only the second as-phrase, as a participant of this course, can (and must) interact with would; the first as-phrase, as a runner, can again only be understood as causal-clause-like.

The present proposal can straightforwardly account for the data in (29). The causal-clause-like interpretation results from a higher syntactic position than either the temporal-clause-like or the conditional-antecedent-like interpretation. Assuming that the height of syntactic attachment is reflected in the surface position of an expression, we expect the relative linear order of cooccurring as-phrases to affect the range of available interpretations.

Stump's account, in contrast, does not predict the relative order of two co-occurring as-phrases to constrain their interpretational possibilities. For any of the two as-phrases in (29b), for instance, their contributed content could be transformed into either the content that underlies the causal-clause-like interpretation (see (4a) in Section 2), or the content that underlies the conditional-antecedent-like interpretation (see (4b) in Section 2). Hence, Stump's account pre- 
dicts (29b) to be ambiguous, contrary to fact.

\section{Limitations of Stump's account and the present account}

In the previous section I presented an account for the semantic variability of weak adjunct asphrases that aimed at capturing the various interpretations that were observed for weak adjuncts in the literature, notably Stump 1985. I proposed that the observed variability is the result of different attachment sites to which weak adjuncts can adjoin. In this respect, my proposal differs from Stump's proposal, who assumes semantic transformations of basic underlying content. In this section, I present data that is problematic for both Stump's and the current proposal. The aim is to identify which of the assumptions about the data need to be revised, and which patterns ultimately need to be captured.

The main problem for both accounts is connected to the conditional-antecedent-like interpretation. The analysis in both accounts predicts that weak adjuncts can behave just like conditional clauses (e.g., if-clauses). Despite some parallels between weak adjuncts and conditional clauses $^{19}$, this is not borne out. In fact, closer examination of the data shows that the interaction between weak adjuncts and modal operators is restricted to a specific subset of modal operators (pace Stump 1985) that can be shown to pattern together in other respects, as well. ${ }^{20}$

\subsection{Differences between if-clauses and weak adjunct $a s$-phrases}

The first difference between $a s$-phrases and if-clauses is that $a s$-phrases depend on the presence of an overt modal operator for their conditional-antecedent-like interpretation. If-clauses, in contrast, can also restrict covert modals (see Kratzer 2012). Compare (30a) to (30b).

a. If Peter is an administrator, he has his office on the third floor.

b. As an administrator, Peter has his office on the third floor.

Even though the main clause in (30a) does not contain an overt modal, the if-clause is interpreted as a conditional antecedent. This is attributed to the presence of a covert epistemic universal modal, similar to overt must, that is restricted by the if-clause. In contrast, the asphrase in (30b) can only be understood with a causal-clause-like interpretation; the conditionalantecedent-like interpretation is, crucially, unavailable.

Neither Stump's account nor the present account can capture this difference. Stump's interpretation rules are designed to assimilate weak adjuncts to if-clauses so that exactly the same combination rules can apply to the two types of expressions. Whether the modal operator involved is overt or covert should not make a difference for the applicability of these rules. The same holds for the present account. The adjunction site that allows an $a s$-phrase to modify $f_{c b}$

\footnotetext{
${ }^{19}$ For instance, $a s$-phrases in their conditional-antecedent-like interpretation can conjoin with if-clauses, see (i).

(i) As an adult and if he had had enough money, Peter could have watched the movie.

${ }^{20}$ For reasons of simplicity, I will restrict the subsequent discussion to if-clauses. Similar observations can be made for conditional clauses introduced by other subjunctors (e.g., when or whenever).
} 
is available whenever a modal operator is present and does not depend on its (c)overtness.

The second difference between as-phrases and if-clauses regards the types of overt modal operators that they can restrict. Stump (1985: 53-57) argues that weak adjuncts can restrict any modal with any interpretation, just like if-clauses. This is in fact not the case. Closer inspection shows that weak adjunct as-phrases are able to restrict future-oriented will, futureoriented might, would, and other subjunctive marked modals. They, however, do not interact with modals in the indicative with an epistemic or root interpretation (i.e., deontic, bouletic, teleological, or ability; see Portner 2009). Compare (31)-(33) to (34)-(36).

(31) [Context: Peter's aunt loves caviar, but she could never afford to buy it. Last week, she learnt that she was going to inherit a lot of money from a rich, distant relative when they were going to die.]

Peter: As a millionaire, she will eat caviar every day.

(future-oriented will)

(32) [Context: Mary asks Susan whether it would be a good idea to have Peter join the day cruise on the Charles River.] (future-oriented might)

Susan: As a participant, Peter might annoy the other passengers on the boat, and the trip would not be as nice.

(33) [Context: Peter was murdered. He died from a blow to the head. The detective knows that the cook is innocent because she has an alibi for the time of the murder. Nevertheless, he considers how the cook would have killed Peter.] (would) Detective: As the culprit, the cook would have used her favorite frying pan.

Examples (31)-(33) contain future-oriented will/might and would, and in these examples, the contribution of the as-phrases can be paraphrased with the corresponding if-clauses. This is, in fact, the only available interpretation of (31)-(33) given the contexts that are provided: the causal-clause-like interpretation requires it to be established (based on what the speaker knows) that the property contributed by the $a s$-phrase applies to the associated individual at the time of utterance; this is not the case in any of the scenarios. ${ }^{21}$ Hence, the observation that the utterances in (31)-(33) are coherent in the given contexts allows us to conclude that the conditionalantecedent-like interpretation is in fact available. Matters are different in (34)-(36).

(34) [Context: Peter was murdered. He died from a blow to the head. The detective believes that either the gardener or the butler did it.] (intended: epistemic might) Detective: \#As the culprit, the gardener might have used his spade. The spade fits with Peter's injuries.

(35) [Context: Peter was beaten up. The main suspect at this point in the investigation is Peter's cook, who has a criminal record.] (intended: deontic have to) Detective: \#As the culprit, the cook has to go to jail.

\footnotetext{
${ }^{21}$ This follows from the observation that as-phrases in their causal-clause-like interpretation pattern with sinceclauses; see Iatridou 1991 and Charnavel 2017.
} 
(36) [Context:] The candidates for the local election will be announced today. Peter knows that Susan was considering to run for office, but he doesn't know what she decided to do in the end.

(intended: bouletic/teleological must) Peter: \#As a candidate, Susan must overcome her awkwardness (to have a chance).

Examples (34)-(36) were constructed using the same strategy as in (31)-(33) to exclude the causal-clause-like interpretation. Hence, the conditional-antecedent-like interpretation would be the only plausible interpretation for these as-phrases. Since the native speakers I consulted uniformely judge the utterances in (34)-(36) as odd in the given contexts, I conclude that the conditional-antecedent-like interpretation is unavailable for the as-phrases in (34)-(36).

In sum, we find that the conditional-antecedent-like interpretation depends on the presence of an overt modal that is not an indicative modal with an epistemic or root interpretation. Neither Stump's analysis nor the proposal in Section 3 can account for these restrictions; in the two analyses, the availability of the conditional-antecedent-like interpretation is fully independent of the properties of the co-occurring modal operator.

\subsection{Modals allowing for the conditional-antecedent-like interpretation}

What is the property that future-oriented will, future-oriented might, would, and other subjunctive-marked modals share that might be decisive for the availability of the conditional-antecedent-like interpretation? Looking at the assortment of modals, one might suspect that the factor that decides which modals interact with weak adjuncts is future temporal orientation. Futureorientedness, however, turns out not to make the right distinction: root interpretations are assumed to be uniformely future-oriented but do not show any interaction with weak adjuncts (see Rullmann and Matthewson 2017). ${ }^{22}$

Closer inspection reveals that future-oriented will differs from future-oriented might, would, and other subjunctive-marked modals and has to be considered independently. The decisive difference between will and the other modals in this group is that the conditional-antecedentlike interpretation with will cannot be subject to "iffiness" (i.e., the speaker has to be relatively certain that the $a s$-phrase content will apply to the associated individual, see von Fintel and Iatridou 2002). This lack of "iffiness" is reflected in the observation that with future-oriented will, the as-phrase has to be paraphrased with a when-clause instead of an if-clause; compare (31) to (32) and (33). This suggests that the interaction of weak adjuncts with will is closer to the interaction with temporal operators than the interaction with the other modals. For reasons of space, the necessary details need to be left to future work.

The remaining modal operators (i.e., future-oriented might, would, and other subjunctivemarked modals) are all irrealis modals. They share the ability to occur in different varieties of past- and future-oriented subjunctive conditionals (see Iatridou 1991 for an overview). In addition, they all (at least diachronically) feature some form of morphological irrealis marking

\footnotetext{
${ }^{22}$ Similarly, the decisive factor cannot be temporal perspective, either. All modals can have either past or present temporal perspective. For a discussion of these notions see Rullmann and Matthewson 2017.
} 
(i.e., some form of past tense and/or subjunctive marking).

Semantically, irrealis modals differ from all other modals and modal flavours, which I will call "realis" modals/flavors, in that irrealis modals can access various linguistically or contextually provided material to "build" their restrictors in case these are not provided by overt material. This ability of irrealis modals is reflected in the following two ways. First, irrealis modals in simple subjunctives are able to extract their restrictors from topic-marked, presupposed, and presumed material (see Kasper 1992, Schueler 2008). The modal would in (37a), for instance, can be restricted by a precondition of Peter's passing the test-i.e., that Peter takes part in the test. In contrast, the deontically interpreted modal have to in (37b) cannot be understood as restricted in the same way.
a. Peter would have passed the test.
(irrealis would) $(\approx$ If Peter had written the test, he would have passed it.)
b. Peter has to pass the test.
(deontic/realis have to)
(Cannot mean: If Peter writes the test, he has to pass it.)

Second, irrealis modals, in contrast to realis modals, allow for modal subordination (see a.o. Roberts 1989, 2015). The third person singular pronoun it in (38a), which features irrealis might, can be anaphoric to the indefinite NP a bar of chocolate in the preceding sentence. No such anaphoric dependency is available for it in the parallel (38b), which contains realis can.

I could leave a bar of chocolate for you in the fridge.

a. My brother might eat it, though. (irrealis might)
$(\approx$ If I leave a bar of chocolate in the fridge, my brother might eat it.)
b. \#My brother can eat it, though. (realis can)

(Cannot mean: If I leave a bar of chocolate in the fridge, my brother can eat it.)

I argue that it is this property of irrealis modals - the property that allows us to reconstruct their restrictor and that renders modal subordination possible- that underlies the possibility of weak adjuncts to restrict these modals. By assuming this general characteristic, I make two predictions: (i) other temporal/modal operators that allow for contextual restriction allow for modal subordination and vice versa, and (ii) weak adjuncts can have a conditional-antecedentlike interpretation with operators of this kind.

Grounding my judgment on the discussion in the literature about simple subjunctives and modal subordination, prediction (i) seems to be borne out. Other temporal/modal operators that have been argued to pattern with irrealis modals with respect to both phenomena are adverbs of quantification and the generic/habitual operator (see a.o. von Fintel 1994, Krifka et al. 1995, Roberts 1989, 2015). For both adverbs of quantification and the generic/habitual operator, we find that they also interact with weak adjuncts to give a conditional-like interpretation (see Stump 1985). This is illustrated in (39), where the weak adjunct as-phrase is shown to interact with and restrict the adverb of quantification often and the generic/habitual operator. Hence, the second prediction in (ii) is also borne out. 

a. As a passenger of Lufthansa, Peter often compliments the flight attendants. $(\approx$ Often, when Peter flies with Lufthansa, Peter compliments ... )
b. As a passenger of Lufthansa, Peter orders as many beverages as possible. $(\approx$ Whenever Peter flies with Lufthansa, he orders ... $)$

In sum, we see that the modal operators in the restricted class that allows for the conditionalantecedent-like interpretation of weak adjuncts share a property that is also decisive with respect to the availability of other interpretational phenomena. What all of these phenomena have in common is that the temporal/modal operators that are involved in them need to be restrictable by material from the linguistic and extra-linguistic context. The conditional-antecendent-like interpretation of weak adjuncts, hence, illustrates a general distinction among temporal $/$ modal operators, which needs to be addressed further. Since this investigation is beyond the scope of this paper, though, it has to be left for future work.

\subsection{Implications for the account of weak adjunct $a s$-phrases}

The discussion in Sections 4.1 and 4.2 has direct implications for Stump's account and the account presented in Section 3: the conditional-like-interpretation cannot be the result of either a direct semantic transformation (as in Stump 1985), or of weak adjuncts restricting the free restrictor variables provided by temporal/modal operators directly (as in the present account). Instead, the modal facts point us towards an indirect mechanism.

The first step towards this indirect mechanism is to realize that, contrary to what is assumed in Stump 1985 and in Section 3, the content contributed by weak adjunct $a s$-phrases is presuppositional. Example (40) shows that the content contributed by as a child (i.e., that Peter is a child) projects from under entailment cancelling operators: it is neither affected by negation nor interpreted inside questions or conditional antecedents.

\footnotetext{
a. It's not the case that as a child, Peter likes sweets.

b. Does Peter, as a child, like sweets?

c. If Peter, as a child, likes sweets, he is... $\gg$ Peter is a child.
}

This is not an entirely new observation. Jäger (2003) shows for a different type of as-phrases (Class 3 in Zobel 2016, 2017a), that they are presuppositional. He, however, indirectly also argues for a presuppositional analysis of weak adjunct as-phrases because he conflates Class 3 $a s$-phrases with weak adjunct $a s$-phrases (Class 4 in Zobel 2016, 2017a). Even though Jäger's choice to conflate Class 3 as-phrases with weak adjunct as-phrases is problematic (see Zobel 2017a), (40) shows that his observation that some as-phrases contribute presuppositional content extends to weak adjunct as-phrases and, I suggest, to weak adjuncts in general.

This observation has, of course, direct consequences for the temporal-clause-like and the causalclause-like interpretation of weak adjuncts. In fact, most aspects of Stump's account and the account presented in Section 3 need to be reconsidered. One aspect of the present account 
should, however, be preserved. From the discussion of the advantages of that account in Section 3.5, we have learnt that the linear order (or rather the hierarchical configuration) of two co-occurring as-phrases has an impact on the interpretational possibilities of sentences with two as-phrases. Hence, any proposal that aims to capture the behavior of weak adjuncts in general and weak adjunct $a s$-phrases in particular should combine a presuppositional analysis of their contribution with the observation that the interpretational differences are connected to different syntactic positions. A sketch of an implementation that combines these two desiderata is given in Zobel 2017b. A full account that captures the wider implications discussed above has to await another occasion.

\section{Conclusion}

In the first part of this paper (Sections 2 and 3), I presented and discussed two proposals that aim to account for the semantic variability of weak adjuncts that results from the interaction of weak adjuncts with temporal or modal operators: (i) the proposal put forth in Stump 1985 and (ii) a new, alternative account that aims to capture the full range of interpretational possibilities of weak adjuncts by connecting the different interpretations to different adjunction sites. I argued that the latter account is to be preferred because it allows us to capture the lack of ambiguity of sentences that contain more than one weak adjunct as-phrase.

In the second part of the paper (Section 4), I showed that the interaction between weak adjuncts and modal operators is much more restricted than previously assumed, which leads to problems for both accounts presented before. We observed that the conditional-antecedent-like interpretation of weak adjuncts is only available with a subset of modal expressions: future-oriented will, future-oriented might, would, and other subjunctive-marked modals. I connected this subset to two other phenomena, simple subjunctives and modal subordination, and argued that the central, shared characteristic of these expressions is their ability to access certain contextually given material to "construe" missing restrictors. Weak adjuncts, I argued, provide material of the necessary kind - they contribute presuppositional content.

Together, these two parts identified two general desiderata for an adequate analysis of weak adjuncts: a proposal for the semantics of weak adjuncts should assign to them presuppositional content and be sensitive to their syntactic adjunction site.

\section{References}

Adler, A. N. (2006). Syntax and Discourse in the Acquisition of Adjunct Control. Ph. D. thesis, MIT, Cambridge, MA.

Asher, N. and A. Lascarides (2003). Logics of Conversation. Cambridge University Press.

Beck, S. and A. von Stechow (2015). Events, times and worlds - an LF architecture. In

C. Fortmann (Ed.), Situationsargumente im Nominalbereich. Linguistische Arbeiten Bd. 562, pp. 13-46. Berlin: De Gruyter.

Carlson, G. (1977). Reference to Kinds in English. Ph. D. thesis, UMass, Amherst.

Charnavel, I. (2017). Non-at-issueness of since-clauses. In Proceedings of SALT 27, pp. 43-58.

Emonds, J. (1984). The prepositional copula as. Linguistic Analysis 13, 127-144. 
Flaate, I. (2007). Die “als”-Prädikative im Deutschen. Eine syntaktisch-semantische Analyse (Studien zur deutschen Grammatik 71). Stauffenburg.

Heim, I. and A. Kratzer (1998). Semantics in Generative Grammar. Blackwell.

Iatridou, S. (1991). Topics in conditionals. Ph. D. thesis, MIT, Cambridge, MA.

Ippolito, M. (2013). Subjunctive Conditionals. A Linguistic Analysis. Cambridge, MA: MIT Press.

Jäger, G. (2003). Towards an explanation of copula effects. Linguistics and Philosophy 26, $557-593$.

Kasper, W. (1992). Presuppositions, composition, and simple subjunctives. Journal of Semantics 9, 307-331.

Kratzer, A. (1977). What "must" and "can" must and can mean. Linguistics and Philosophy 1, $337-355$.

Kratzer, A. (2012). Modals and Conditionals: New and Revised Perspectives. Oxford University Press.

Krifka, M., F. J. Pelletier, G. N. Carlson, A. ter Meulen, G. Chierchia, and G. Link (1995). The Generic Book, Chapter Genericity: An Introduction, pp. 1-124. UChicago Press.

Matushansky, O. and B. Spector (2005). Tinker, tailor, soldier, spy. In E. Maier, C. Bary, and J. Huitink (Eds.), Proceedings of Sinn und Bedeutung 9, pp. 226-240.

Montague, R. (1973). The proper treatment of quantification in ordinary English. In J. Hintikka, A. Moravcsik, and P. Suppes (Eds.), Approaches to Natural Language, pp. 221-242. Dordrecht: Reidel.

Portner, P. (2009). Modality. Oxford University Press.

Roberts, C. (1989). Modal subordination and pronominal anaphora in discourse. Linguistics and Philosophy 12, 683-721.

Roberts, C. (2015). Modal subordination: It would eat you first! To appear in L. Matthewson, C. Meier, H. Rullmann, and T. E. Zimmermann (eds.), Companion to Semantics. Wiley.

Rullmann, H. and L. Matthewson (2017). Towards a theory of modal-temporal interaction. To appear in Language.

Schueler, D. E. (2008). The Syntax and Semantics of Implicit Conditionals: Filling In the Antecedent. Ph. D. thesis, UCLA.

Stump, G. T. (1985). The Semantic Variability of Absolute Constructions. Dordrecht: Reidel. von Fintel, K. (1994). Restrictions on Quantifier Domains. Ph. D. thesis, UMass, Amherst. von Fintel, K. and S. Iatridou (2002). If and when if-clauses can restrict quantifiers. Manuscript, MIT.

von Stechow, A. (2004). Modale und Konditionale. Teaching materials for a seminar on modality and conditionals, Vienna, May 2004.

Williams, E. (1992). Adjunct control. In R. Larson, S. Iatridou, U. Lahiri, and J. Higginbotham (Eds.), Control and Grammar. Dordrecht: Kluwer.

Zobel, S. (2016). Adjectival as-phrases as intensional secondary predicates. In M. Moroney, C.-R. Little, J. Collard, and D. Burgdorf. (Eds.), Proceedings of SALT 26, pp. 284-303.

Zobel, S. (2017a). A classification of German als-phrases and English as-phrases. Ms. University of Tübingen.

Zobel, S. (2017b). The restrictive potential of weak adjuncts: nominal 'as'-phrases and individual quantifiers. In A. Cremers, T. van Gessel, and F. Roelofsen (Eds.), Proceedings of the 21 st Amsterdam Colloquium, pp. 521-530. Amsterdam: ILLC. 